\title{
ANTAGONISTIC MECHANISM OF $\alpha$-MANGOSTIN DERIVATIVES AGAINST HUMAN ESTROGEN RECEPTOR A OF BREAST CANCER USING MOLECULAR DYNAMICS SIMULATION
}

\author{
M. Muchtaridi ${ }^{1}$, S. Megantara ${ }^{1},{ }^{*}$, D. Dermawan ${ }^{1}$ and M. Yusuf ${ }^{2}$ \\ ${ }^{1}$ Department of Pharmaceutical Analysis and Medicinal Chemistry, Faculty of Pharmacy, \\ Universitas Padjadjaran, Indonesia \\ ${ }^{2}$ Department of Chemistry, Faculty of Mathematics and Natural Sciences, \\ Universitas Padjadjaran, Indonesia \\ *E-mail: s.megantara@unpad.ac.id
}

\begin{abstract}
1,3,6-trihydroxy-7-methoxy-2,8-bis(3-methylbut-2-enyl)xanthen-9-one ( $\alpha$-mangostin) that isolated from Garcinia mangostana pericarp has anti-proliferative activity related to tumor growth suppression and inhibit the growth of MCF-7 breast cancer through the decreased function of human estrogen receptor $\alpha(\mathrm{hER} \alpha)$. This study aimed to modify $\alpha$-mangostin and investigate its molecular interactions in order to increase its activity as an antagonist of $\mathrm{hER} \alpha$ of breast cancer using computational simulation approaches. Molecular docking and molecular dynamics simulation were employed to identify the molecular interactions of $\alpha$-mangostin derivatives against hER $\alpha$ (PDB ID: 3ERT). The results showed that the binding energy of the best derivative of $\alpha$-mangostin (AMD10) was -11.89 $\mathrm{kcal} / \mathrm{mol}$ compared to estradiol (agonist) was $-10.12 \mathrm{kcal} / \mathrm{mol}$. The results of molecular dynamics simulation using the Molecular Mechanics Poisson-Boltzmann and Surface Area (MM-PBSA) calculation method showed that AMD10 has a better affinity with a value of $\Delta \mathrm{GTotal}=-52.57 \mathrm{kcal} / \mathrm{mol}$ compared to estradiol was amounted to $\Delta \mathrm{GTotal}=-40.86 \mathrm{kcal} / \mathrm{mol}$. These results showed that AMD10 is a promising candidate for novel anti-breast cancer agents with antagonistic activity to $\mathrm{hER} \alpha$.
\end{abstract}

Keywords: $\alpha$-Mangostin, Breast Cancer, hER $\alpha$, Molecular Docking, Molecular Dynamics

(C) RASĀYAN. All rights reserved

\section{INTRODUCTION}

Cancer is one of the leading causes of death, and its burden rises to 18.1 million new cases caused 9.6 million cancer deaths in 2018. Breast cancer is the top three cancer type in terms of incidence and is ranked within the top five in terms of mortality. ${ }^{1}$ Human estrogen receptor $\alpha(\mathrm{hER} \alpha)$ is the primary prognostic marker used to investigate tumors in breast tissue. ${ }^{2} \mathrm{hER} \alpha$ is an activated receptor by transcriptional regulatory mechanism which is the primary regulator for differentiation and proliferation of breast cells. ${ }^{3}$ This receptor plays an essential role in the progression and development of a dependent hormonal type of breast cancer. ${ }^{4}$

Molecular design, modeling, and simulation-based on computational methods have been widely employed in chemistry and pharmaceutical sciences to generate the information about the mechanism of molecular reactions among compounds and in order to accelerate the new molecule discovery effort. ${ }^{5}$ The algorithms and equations of calculation in the computational method can predict the actual experimental results when the system conditions before laboratory trials. ${ }^{6}$ One of the sophisticated methods to obtain a novel drug for breast cancer is molecular modeling of the potential molecule which has an antagonist activity to hER $\alpha$. $\alpha$-Mangostin is the primary active secondary metabolite derived from Garcinia mangostana pericarp that has anti-proliferative activity related to tumor growth suppression and inhibits the growth of MCF-7 breast cancer through the decreased function of hER $\alpha .^{7} \alpha$-Mangostin has anti-

Rasayan J. Chem., 12(4), 1927-1934(2019)

http://dx.doi.org/10.31788/RJC.2019.1245391

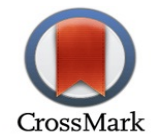


RASĀYAN J. Chem.

Vol. 12 | No. 4 |1927 - 1934| October - December | 2019

proliferative activity against MCF-7 adenocarcinoma cell with $\mathrm{IC}_{50}$ by $20 \mu \mathrm{g} / \mathrm{mL}{ }^{8}$ That $\mathrm{IC}_{50}$ value included in the not very active category ranged from 10 to $100 \mu \mathrm{g} / \mathrm{mL}$. ${ }^{9}$ Therefore, this study aimed to modify $\alpha$-mangostin and investigate its molecular interactions in order to increase its activity as an antagonist of $\mathrm{hER} \alpha$ of breast cancer using molecular docking and molecular dynamics simulation.

\section{EXPERIMENTAL}

\section{Molecular Docking Simulation}

The receptor was the X-ray crystallography derived hER $\alpha$ in complex with estradiol downloaded from Protein Data Bank (PDB) with PDB ID: 1 G50.$^{10}$ The three-dimensional structures of $\alpha$-mangostin and its derivatives as ligand were optimized by ChemDraw Ultra 12.0 (PerkinElmer Inc.) and LigandScout Advanced 4.1 (Inte: Ligand GmbH, Vienna, Austria). ${ }^{11}$ The grid parameter file was according to the grid box comprised of $40 \times 40 \times 40$ points size with $0.375 \AA$ of space value and was centered on the active pocket of $\mathrm{hER} \alpha(\mathrm{x}=30.010, \mathrm{y}=-1.913$, and $\mathrm{z}=24.207)$. AutoDockTools 4.2 (The Scripps Research Institute) was employed to do the molecular docking simulation. The docking parameter file was according to Lamarckian Genetic Algorithm (LGA) with: 100 number of runs, 2.500.000 energy evaluation, 150 population size, 0.02 rate of gene mutation and 0.8 rate of crossover. ${ }^{12}$

\section{Molecular Dynamics (MD) Simulation}

The molecular dynamics (MD) simulation was performed on two ligand-receptor systems including $\mathrm{hER} \alpha$ - estradiol (agonist) and $\mathrm{hER} \alpha-\alpha$-mangostin derivative with the best affinity (antagonist). The simulation was done using AMBER14, the ligands were parameterized using the Antechamber module with AM1-BCC calculation method. ${ }^{13}$ Then, $\mathrm{Cl}^{-}$ion was added as counter ion using LEAP module. The explicit water model of TIP3P box was added into system as the disolvation process. The energy minimization of each system was performed by Sander module in AMBER $14 .{ }^{14}$ This minimization process was done in order to eliminate steric hindrances and remove atoms and/or clusters that could cause a collision among atoms. These molecular contacts were removed to maintain the energy at low state within the area during the molecular dynamics simulation. The energy minimization was performed on the heating intended system gradually from $0-100^{\circ} \mathrm{K}, 100-200^{\circ} \mathrm{K}$ then $200-310^{\circ} \mathrm{K}$ until reached the equilibrium state at approximately $37^{\circ} \mathrm{C}$ (normal human physiological body temperature) with harmonic restraint of $5.0 \mathrm{kcal} . \mathrm{mol}^{-1} \cdot \mathrm{A}^{-2}$ on the backbone atoms. The MD simulations were done for $50 \mathrm{~ns}$ with a constant temperature of $310^{\circ} \mathrm{K}$.

\section{RESULTS AND DISCUSSION}

\section{Molecular Docking Simulation}

The results of molecular docking simulation of estradiol, $\alpha$-mangostin and its derivatives can be seen in Table-1. These results showed that $\alpha$-mangostin derivatives (AMD)4, AMD6, AMD7, AMD8, AMD9, and AMD10 have a better affinity to $\mathrm{hER} \alpha$ than estradiol and the basic structure of $\alpha$-mangostin itself.

Table-1: The Molecular Docking Simulation Results of $\alpha$-Mangostin and its Derivatives in the Ligand-binding Domain of hER $\alpha$

Molecule
Name


RASĀYAN J. Chem.

Vol. 12 | No. 4 |1927 - 1934| October - December | 2019

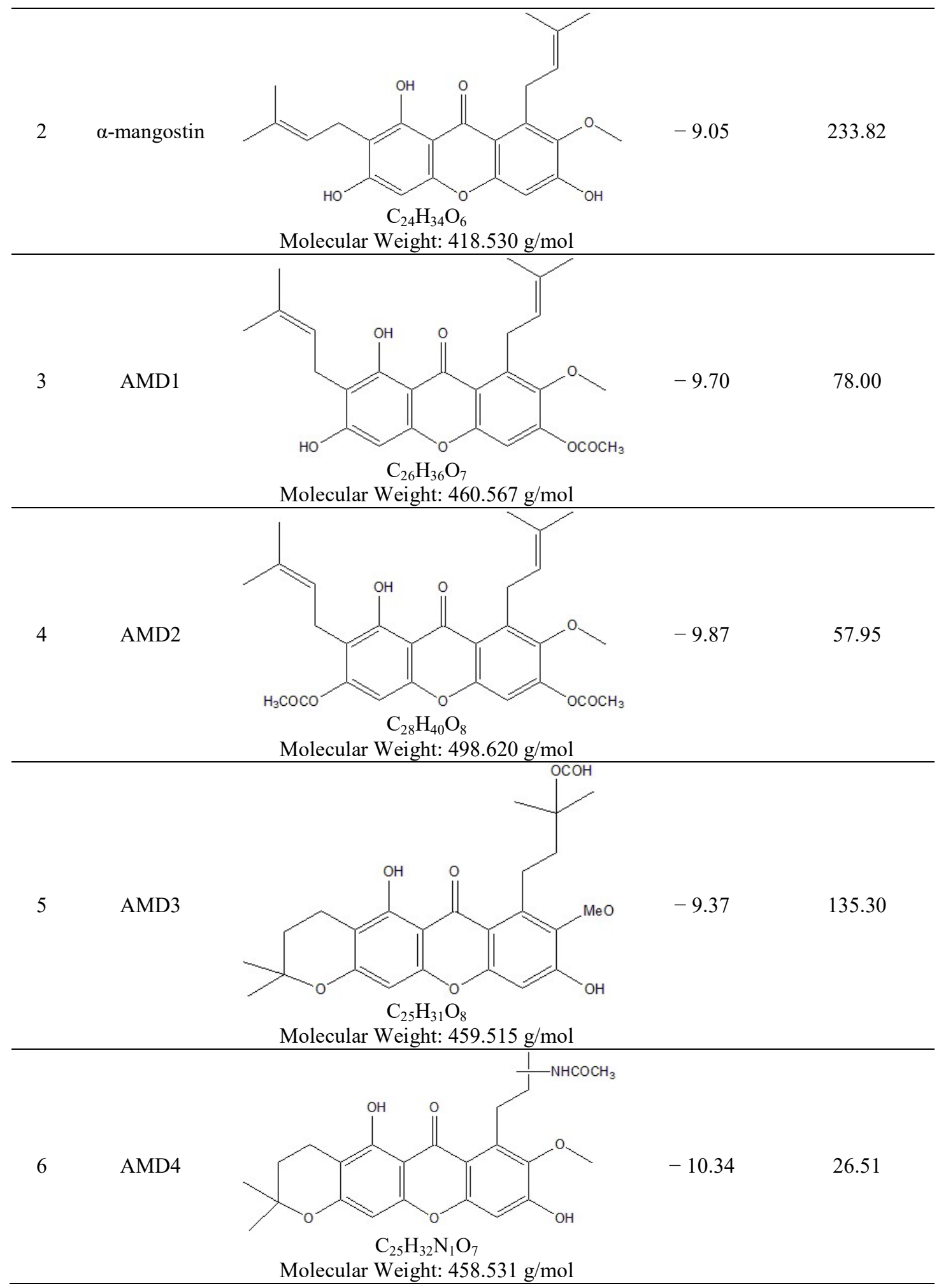


RASĀYAN J. Chem.

Vol. 12 | No. 4 |1927 - 1934| October - December | 2019
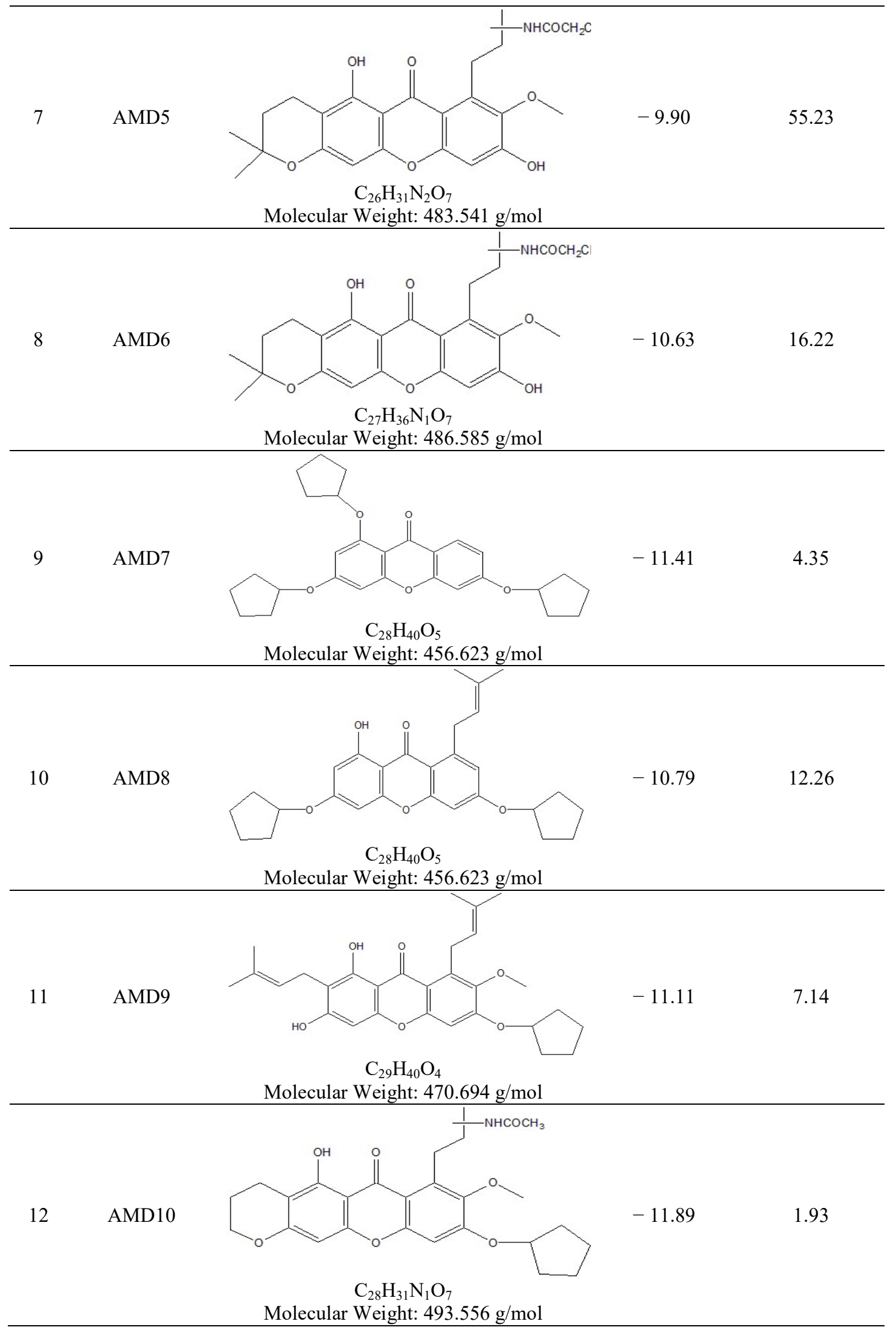

Molecular Weight: $493.556 \mathrm{~g} / \mathrm{mol}$ 
RASĀYAN J. Chem.

Vol. 12 | No. 4 |1927 - 1934| October - December | 2019

The Gibbs energy $(\Delta \mathrm{G})$ of $\alpha$-mangostin derivatives were ranged from $-9.37 \mathrm{kcal} / \mathrm{mol}$ to $-11.89 \mathrm{kcal} / \mathrm{mol} \mathrm{compared}$ to the estradiol $(-10.12 \mathrm{kcal} / \mathrm{mol})$ and basic $\alpha$-mangostin $(-9.05 \mathrm{kcal} / \mathrm{mol})$ and the lowest $\Delta \mathrm{G}$ was AMD10 ($11.89 \mathrm{kcal} / \mathrm{mol})$.

\section{Molecular Dynamics (MD) Simulation}

The results obtained after going through the production phase of molecular dynamics simulation of estradiol and AMD10 as the best $\alpha$-mangostin derivative were Root Mean Square Deviation (RMSD), Root Mean Square Fluctuation (RMSF), and total binding energy obtained using the Molecular Mechanics-Poisson Boltzmann Surface Area (MM-PBSA) method.

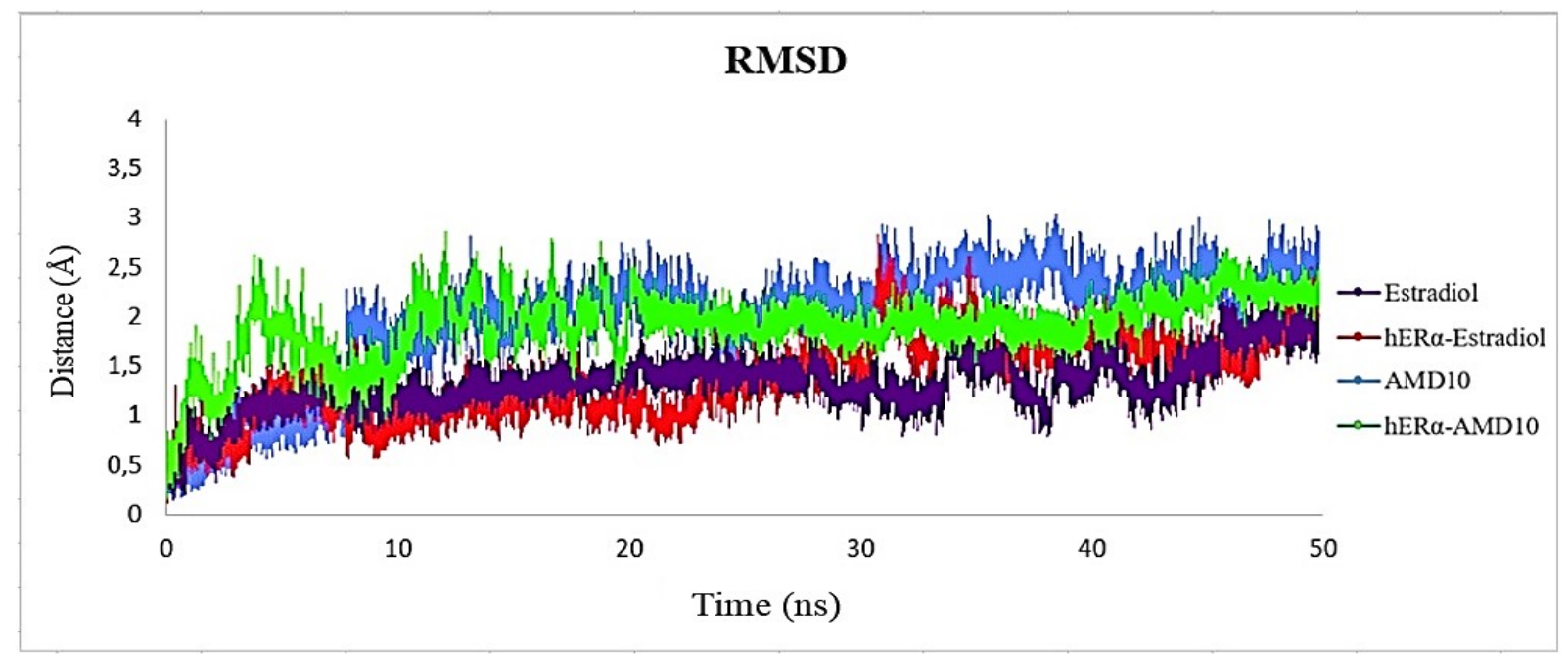

Fig.-1: Root Mean Square Deviation (RMSD) of AMD10

AMD10 has a high deviation value compared to estradiol. In hER- $\alpha$ complexed with AMD10, the movement of residues was increased compared to hER- $\alpha$ complexed with estradiol.

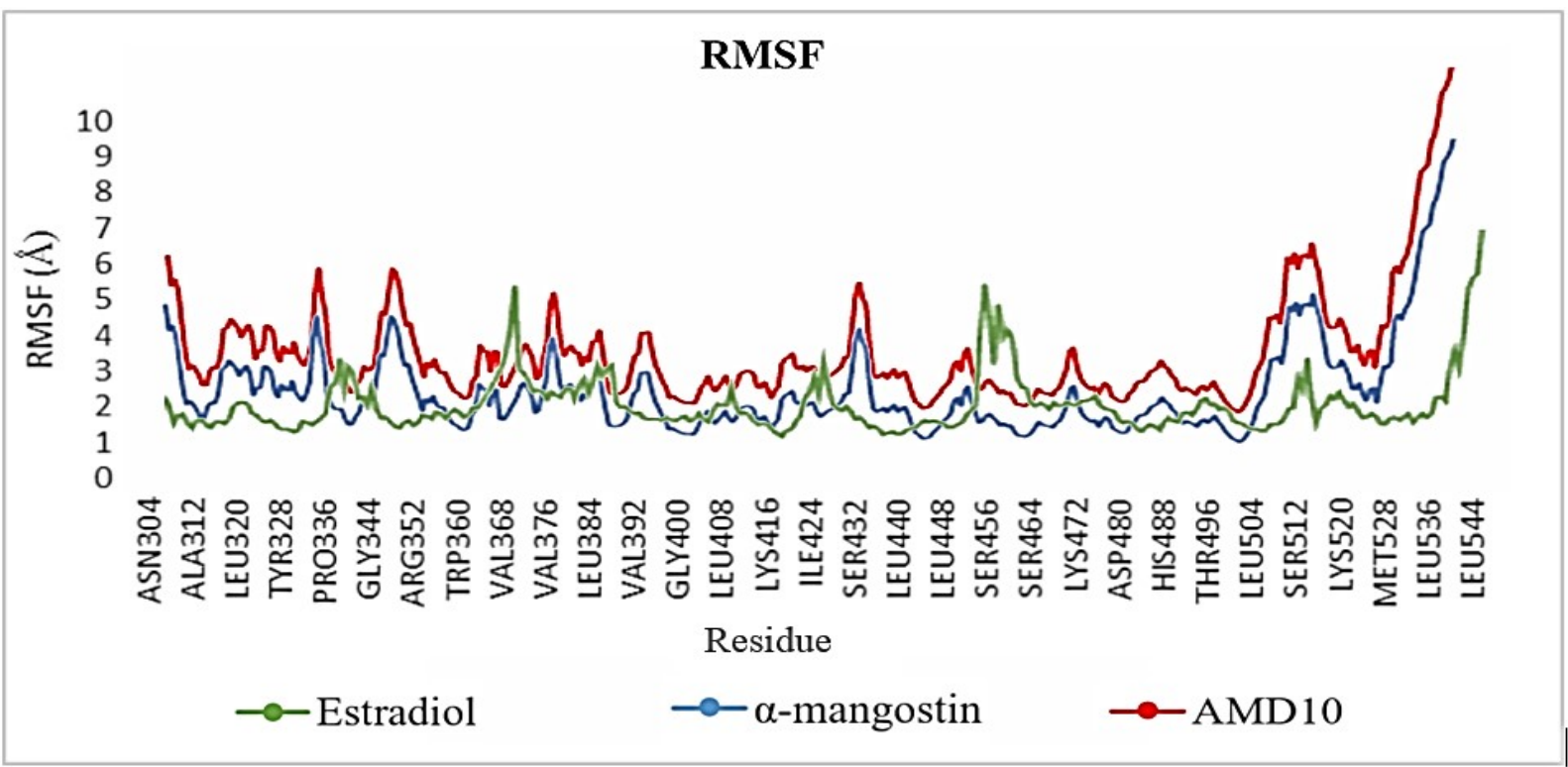

Fig.-2: Root Mean Square Fluctuation (RMSF) of AMD10

The hER $\alpha$ crystal has a hydrogen bond that formed between GLU419 and LYS 531 and GLU419 with HIS524. In the AMD10-hER $\alpha$ complex, the disruption of hydrogen bonds formed between GLU419His524, with an increased fluctuation in the residues of Ser432 and Ser521. 
RASĀYAN J. Chem.

Vol. 12 | No. 4 |1927 - 1934| October - December | 2019

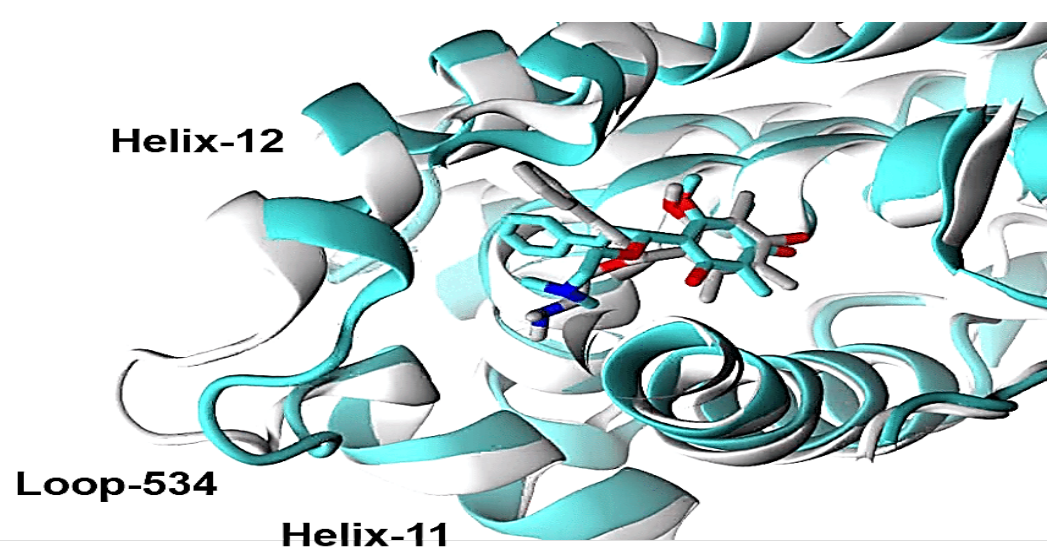

Fig.-3: Comparison Loop-534 of AMD10 (Blue) Complex was more elevated than Estradiol (White). Loop-534 is the region between Helix-11 and Helix-12 that accommodate the Antagonistic Activity of a Ligand. ${ }^{14}$

In the hER- $\alpha$ antagonist receptor, HIS524 residues have a fluctuation movement while the agonistreceptor structure is more stable. ${ }^{14}$ In complexes with AMD10, loop-534 was more flexible than estradiol. Thus, AMD10 has the potential to be an hER $\alpha$ antagonist.

Table-2: Energy Calculation of the Binding System of AMD10 using the MM-PBSA Method.

\begin{tabular}{|c|c|c|}
\hline \multirow{2}{*}{ Energy Component (kcal/mol) } & \multicolumn{2}{|c|}{ System } \\
\hline & hER $\alpha-$ Estradiol & $\mathrm{hER} \alpha-\mathrm{AMD} 10$ \\
\hline Van der Waals (VdW) interaction & -44.87 & -58.72 \\
\hline Electrostatic Energy (EEL) & 1.16 & -8.87 \\
\hline $\begin{array}{l}\text { Electrostatic contribution to } \\
\text { solvation-free energy }\left(\mathrm{E}_{\mathrm{GB}}\right)\end{array}$ & 7.39 & 20.56 \\
\hline Surface area energy $\left(\mathrm{E}_{\mathrm{SURF}}\right)$ & -4.54 & -5.54 \\
\hline$\Delta$ Ggas $(\mathrm{VdW}+\mathrm{EEL})$ & -43.71 & -67.59 \\
\hline$\Delta$ Gsolv $\left(\mathrm{E}_{\mathrm{GB}}+\mathrm{E}_{\mathrm{SURF}}\right)$ & 2.85 & 15.02 \\
\hline $\begin{array}{c}\Delta \mathrm{G}_{\mathrm{TOTAL}} \\
\left(\mathrm{VdW}+\mathrm{EEL}+\mathrm{E}_{\mathrm{GB}}+\mathrm{E}_{\mathrm{SURF}}\right)\end{array}$ & -40.86 & -52.57 \\
\hline
\end{tabular}

The $\Delta \mathrm{G}$ Total of AMD10 value was smaller than estradiol. Demonstrating, AMD10 has a better affinity compared to estradiol against the $\mathrm{hER} \alpha$.

The selected receptor for molecular docking and MD simulations was the x-ray structure of hER $\alpha$ that complexed with estradiol (PDB ID: 1G50) based on an experimental resolution (2.9 $\AA$ ), R-value free (0.310), and R-value work (0.241). ${ }^{10}$ In molecular simulations, ligands having agonist or antagonistic activity against $\mathrm{hER} \alpha$ are determined by the flexible helix-12 region of the amino acid residue 536-544. When a ligand has the hydrogen bond with His524 residue, it means the ligand has the agonistic activity to hER.$^{14}$

The trajectory analysis of molecular dynamics simulation results was carried out using the cpptraj module from AMBER14 software. Root Mean Square Deviation (RMSD) value is a deviation or comparison between the conformation system of the ligand-receptor complex during the simulation process and the system confirmation in the initial state before the simulation. The RMSD value is defined by a unit of distance in angstrom $(\AA)$ mapped using the xmgrace module on the AMBER14 software. The RMSD value can be seen in Fig.-1. The system achieved general stability after the simulation runs at 20 ns which can be seen in Fig.-1 where the hER $\alpha$-AMD10 complex has a higher RMSD value (around 2.5-2.7 $\AA$ ) compared to the $\mathrm{hER} \alpha-$-estradiol complex $(\leq 2 \AA)$. This result indicated that the flexibility value of $\mathrm{hER} \alpha$ receptors that interact with AMD10 ligands was higher and folds occur in the structure of the hER $\alpha$ receptor protein. The trajectory analysis of the simulation results was also carried out on the value of Root Mean Square Fluctuation (RMSF). RMSF value is a condition of fluctuations in amino acid residues that 
RASĀYAN J. Chem.

Vol. 12 | No. 4 |1927 - 1934| October - December | 2019

compile the receptors during the simulation process. Fluctuations represent the flexibility of amino acid residues. Like the RMSD value, the determination of the RMSF value was also mapped using the xmgrace module on the AMBER14 software. RMSF values can be seen in Fig.-2. Based on Fig.-2, it is known that the flexibility of amino acid residues was influenced by the type of ligand that interacts with the receptor. AMD10 ligands result in higher residual fluctuations compared to $\alpha$-mangostin and estradiol where fluctuations in the estradiol complex were the least fluctuating. The residues that experienced the highest fluctuations due to $\alpha$-mangostin and AMD10 were Pro336, Arg352, Val376, Ser432, Ser512, and Met528. Whereas, the residues that experienced the highest fluctuations caused by estradiol were Val368, Ile424, Ser456, Ser512, and Leu544.

The structure of the hER $\alpha$ protein has hydrogen bonds to the constituent amino acid residues, namely between Glu419 with His524 and Glu419 with Lys531. If there is a disruption to the hydrogen bond which can be represented by fluctuations by a ligand, the ligand has the potential as an antagonist to the $\mathrm{hER} \alpha$ receptor. This molecular interaction caused a lack of hydrogen bond known as a zipper network in a ligand structure with agonistic activity. This zipper network was built between residues of GLU419, HIS524, and LYS531 that has an essential role in making sure that Helix-3 and Helix-11 of hER $\alpha$ are still in close contact. ${ }^{15,16} \alpha$-Mangostin and AMD10 disrupted the hydrogen bond with fluctuations with Ser432 and Ser521 residues so that it can be said that $\alpha$-mangostin and AMD10 have antagonistic activity against hER $\alpha$. Then in Fig.-3, it is known that in loop-534, AMD10 ligands were more geometrically elevated than estradiol as $\mathrm{hER} \alpha$ agonists.

Based on Table-2, it is known that the hER $\alpha$-AMD10 system has a lower free binding energy value compared to the $\mathrm{hER} \alpha$-estradiol system where the Van der Waals (VdW) interaction energy was the energy component that has the most significant influence on the system. ${ }^{17}$ The energy of VdW interaction in the hER $\alpha$ system-AMD10 was lower due to the more extended AMD10 structure. The contribution of enormous VdW interaction energy to the system indicates that hydrophobic residues dominated the amino acid residues that compile the active site of the $\mathrm{hER} \alpha$ protein. The total value of free binding energy $(\Delta \mathrm{G})$ of $\mathrm{hER} \alpha-$ AMD10 system $(-52.57 \mathrm{kcal} / \mathrm{mol})$ was lower than the $\mathrm{hER} \alpha$-estradiol system, these results showed that the affinity level of AMD10 (antagonist) to hER $\alpha$ was better than estradiol as an agonist with a total value of $\Delta \mathrm{G}$ amounted to $-40.86 \mathrm{kcal} / \mathrm{mol}$.

\section{CONCLUSION}

The most important interactions of $\alpha$-mangostin derivatives with the hER $\alpha$ as the targeted receptor consists of the hydrogen bonds and hydrophobic interactions. Among the all designed $\alpha$-mangostin derivatives, AMD10 was the best derivative identified by molecular docking and molecular dynamics simulation. The results of molecular dynamics simulation using MMPBSA calculation method showed that AMD10 has a better affinity with a value of $\Delta$ GTotal $=-52.57 \mathrm{kcal} / \mathrm{mol}$ compared to estradiol amounted to $\Delta \mathrm{GTotal}=-40.86 \mathrm{kcal} / \mathrm{mol}$. These results showed that $\mathrm{AMD} 10$ is a promising candidate for novel anti-breast cancer agents with antagonistic activity to $\mathrm{hER} \alpha$. It is necessary to synthesize the bestmodified compounds from $\alpha$-mangostin (AMD10). In vitro and in vivo tests are needed to ensure the activity of AMD10 compound as anti-breast cancer with the antagonistic to hER $\alpha$.

\section{ACKNOWLEDGMENT}

This study was supported by the Academic Leadership Grants Program No. 1373b/UN6.O/LT/2019 of Universitas Padjadjaran of Indonesia.

\section{REFERENCES}

1. Cancer Burden Rises to 18.1 Million New Cases and 9.6 Million Cancer Deaths in 2018, WHO, 13(2018).

2. T. Mijatovic, E.V. Quaquebeke, B. Delest, O. Debeir, F. Darro and R. Kiss, Biochim. Biophys. ActaRev. Cancer, 1776, 32(2007), DOI:10.1016/j.bbcan.2007.06.002

3. H. Abdel-Hafiz, Diseases, 5, 16(2017), DOI:10.3390/diseases5030016

4. S. Bhatt, J.D. Stender, S. Joshi, G. Wu, B.S Katzenellenbogen, Oncogene., 35, 5722(2016), DOI:10.1038/onc.2016.105 
RASĀYAN J. Chem.

Vol. 12 | No. 4 |1927 - 1934| October - December | 2019

5. R.S. Subrahmanyam, P. Ramesh, B.S. Krishna, S.D. Shanti, D. Khan, M. Ashrafuddin, M.M. Darla, M. Mark, K. Adeppa, B.V. Bhaskar, W. Rajendra and V.R. Anna, Rasayan J. Chem., 10, 1194(2017), DOI:10.7324/RJC.2017.1041838

6. D. Dermawan, N. Wathoni and M. Muchtaridi, Journal of Young Pharmacists. 11, 31(2019), DOI:10.5530/jyp.2019.11.7

7. M. Shibata, M. Iinuma, J. Morimoto, H. Kurose, K. Akamatsu, Y. Okuno, Y. Akao amd Y. Otsuki, BMC Med., 9, 1(2011), DOI:10.1186/1741-7015-9-69

8. H. Kurose, M.A. Shibata, M. Iinuma and Y. Otsuki, J. Biomed. Biotechnol., 2012, 1(2012), DOI: $10.1155 / 2012 / 672428$

9. G. Jones, P. Willett, R.C. Glen, A.R. Leach and R. Taylor, J. Mol. Biol., 267, 727(2002), DOI:10.1006/jmbi.1996.0897

10. Amber 2018 Reference Manual, (2018), http://ambermd.org/doc12/Amber18.pdf

11. G. Wolber and T. Langer, J. Chem. Inf. Model., 45, 160(2005), DOI:10.1021/ci049885e

12. M. Muchtaridi, D. Dermawan and M. Yusuf, J. Young. Pharm., 10, 252(2018), DOI:10.5530/jyp.2018.10.58

13. A.A. Parikesit and U.S.F. Tambunan, Rasayan J. Chem., 11, 1133(2018), DOI: $10.31788 /$ RJC.2018.1133038

14. A.K. Shiau, D. Barstad, P.M. Loria, L. Cheng, P.J. Kushner, D.A. Agard and G.L. Greene, Cell, 95, 927(1998), DOI:10.1016/S0092-8674(00)81717-1

15. I. Musfiroh, Y. Susilawati, M. Muchtaridi, R, Mustarichie, A. Muhtadi, A. Diantini, A.N. Hasanaha, L.Z. Udin, J. Appl. Pharmac. Sci., 03, 7(2013), DOI: 10.7324/JAPS.2013.3602

16. M. Muchtaridi, M. Yusuf, A. Diantini, S. Choi, B. Al-Najjar, J. Manurung, A. Subarnas, T. Achmad, S. Wardhani and H. Wahab, Int. J. Mol. Sci., 15, 7225(2014), DOI:10.3390/ijms15057225

17. B.V. Udugade1 and S. P. Gawade, Rasayan J. Chem., 11, 118(2018), DOI: 10.7324/RJC.2018.1111860

[RJC-5391/2019] 